\section{SECONDARY SYPHILIS COMMUNICATED TO A WET-NURSE.}

\author{
B Y H E N R Y L E E, F.R.C.S.,
} SUBGHON TO ST. GBORGR's hOSPITAC.

A Patient and his wife lately came under my care. The man had had syphilis six years ago. He was then under the care of two hospital surgeons of acknowledged reputation. In six weeks he had a slight eruption on the skin; and six months afterwards he suffered from sore-throat. He took no mercury for the primary affection, but rubbed in some mercurial ointment for six or seven weeks for the secondary disease. There were no subsequent symptoms, and the patient, considering himself well, married four years ago. Three or four weeks after the first impregnation the wife had some spots on her hands; she subsequently lost her hair, and had inflammation of one eyelid. She miscarried with her first child after a fall. She became pregnant again fifteen months after her marriage, and had a dead child at the end of seven months. She then had a living child, which was apparently healthy. It however had an eruption on its skin at the expiration of a month, and died when eleven weeks old. A fourth child was born apparently healthy, and was given to a healthy young woman to nurse. Some spots appeared on the child's mouth when a fortuight old; and it subsequently had eruption in other parts of the body.

I saw the wet-nurse five months after she had commenced nursing the child. There was a circumscribed, oval, elevated, discoloured patch, covered with thick epithelial scales, an inch below and to the outer side of the left nipple. This was of much firmer consistence than the surrounding parts, but wanted the characteristic induration of primary syphilitic sores on other portions of the skin. A gland in the axilla was considerably enlarged, very hard, and accurately circumscribed. The remains of a well-marked, copper-coloured eruption were distinctly visible on different parts of the skin, especially upon the arms. The spot on her breast had commenced, she said, soon after taking the child to nurse. Her own child, which was quite healthy, she had not nursed. She had never suffered from any enlargement of the glands in the groin, nor from any local symptom. Her husband, whom I saw, appeared a perfectly healthy man.

I do not bring this case forward as illustrating any point which is not now perfectly well known; but it affords a very clear and distinct instance of the way in which secondary syphilis may be communicated, and that to more than one individual. Until recently it was held to be impossible that such communication could take place. Judging from the writings of medical men twenty years ago, this seems to have been at that time the almost universally received doctrine. It is greatly to be feared that the boldness with which medical men were accustomed at that time to lay down the law that every primary syphilitic sore must necessarily have proceeded from one similar in kind, has in many instances been the cause of the gravest and the most unjust accusations. The reputation of many a wife has been thus assailed in its tenderest point; the character of nurses has been impugned; and I could cite at least one case, which came under my own personal observation, in which a young maiden was accused of immorality, when she had been infected by using the same spoons and cups as her fellow-servant. In all such cases a double injury is likely to be inflicted. The patient has not only to suffer from a protracted disease which she had no means of avoiding, but is liable to have her fair reputation dishonoured into the bargain. It is to be feared that this cruel injustice has often been fostered, if it has not been originated, by erroneous surgical pathology. If such a serious evil does lie at our door as medical men, it becomes us at once to make what amends wo can, and it is with this view that $I$ have ventured to bring this subject before the profession.

There are also one or two points of a scientific nature that may not be unworthy of attention.

1. The character of the induration of the primary affection, as it appears to me, is different on the breast, and perhaps on the cheek, from that which is more usually observed. The affected portion of skin is doughy and elastic, giving the sensation of india-rubber rather than of cartilage. This indura- tion, in the cases which I have observed on the breast, is not accurately circumscribed, but rather it fades gradually into the consistence of the surrounding parts.

2. The original disease in the husband, in the case related, was treated without mercury; and the secondary affection appears to have been so treated during a very inadequate length of time. This patient may probably have discontinued attending his surgeons of his own accord, on account of his predilection for homœopathy; but, as the case stands, it is not an encouraging one as regards the treatment of real constitu. tional syphilis by a short course of mercury; and still less does it tend to uphold the idea that this disease, in its origin, may safely be left to itself, as appears to be maintained by some who have lately written upon the natural history of syphilis.

Whether the lamentable results in this case are to be attributed to the want of treatment of the original affection; to the insufficient treatment of the secondary disease; to the patient having placed himself under a homœopathic practi. tioner before his surgeon dismissed him; or whether the similar results might have happened under any plan of treat. ment, -I shall not have time at present further to discuss : but I am, at all events, anxious that we should have a clear idea of the pathology of this disease. We may at least hope, if our medicines do no good (which, when properly administered, I am very far from admitting), that our theories shall do no harm; and to this point I would, in conclusion, for a moment revert. It almost always happens, when a fact sup. posed to be new is started, that it is shown within a few brief weeks or months to have been anticipated at some time or other, either in part or altogether. The theory of the commu. nicability of secondary syphilis was held by many of the older writers, although they did not prove its correctness. The idea held possession of some of the best minds independent of any physical proof, as the atomic theory may have been received by many, independent of any chemical experiments. Our great English bard, who knew something of human physiology, although he never, so far as I know, made that his especial study, was quite at home on this subject. In "Measure for Measure," act i., sc. ii., Lucio has a controversy with a gentleman, who twits him with being "piled." Lucio confesses a most painful feeling of his speech, but retorts that "whilst he lives he will forget to drink after him." The gentleman says he is sound. But Lucio replies, "Nay, not as one would say healthy; but so sound as things that are hollow: thy bones are hollow; impiety has made a feast of thee." Shakspeare here clearly alludes to constitutional syphilis, and implies that it may be communicated by a drinking-cup, as in the case of the young woman to which I have referred. Could any doubt for a moment exist as to the nature of the disease to which he refers, it is removed by his allusion in the same passage to the "French crown," which in modern days, with more politeness to our neighbours, we render "corona veneris."

Savile-row, June, 1868 .

\section{CASES IN PRACTICAL SURGERY.}

By T. J. ASHTON,

CONSULTING SURGEON TO THE ST. NARYLEBONE IN FIBMARY.

\section{No. III.}

STRANGULATED HERNIA.

THE cases in previous communications were those of immediate treatment of stricture of the urethra, and amputation of the thigh. The following relate to strangulated hernia relieved by operation.

Femoral hernia; strangulation; operation; recovery.M. A. D-, a female, aged forty-nine, had had femoral hernia of the right side for upwards of twenty years; and although fully acquainted with the nature of her disease, she had never worn a truss. For three days previous to her ad. mission into the intirmary she had suffered from complete con. stipation, attended with tenderness and increase in the size of the tumour; vomiting had supervened, which became stercoraceous soon after her admission. The symptoms being urgent, and several attempts to reduce the hernia having been made without success, my colleague, Dr. Randall, fully concurred with me in the advisability of an immediate operation. Accordingly, the patient having been brought under the influence of chloroform, I cut down on the sac, and the stricture, which was at the internal opening of the femoral canal, was divided by an incision directed upwards and inwards. The sac con. 